The University of San Francisco

USF Scholarship: a digital repository @ Gleeson Library |

Geschke Center

School of Education Faculty Research

School of Education

2010

\title{
Alone and In Between Cultural and Academic Worlds: Voices of Samoan Students
}

\author{
Noah E. Borrero \\ University of San Francisco, neborrero@usfca.edu \\ Christine J. Yeh \\ University of San Francisco, cjyeh@usfca.edu \\ Patsy Tito \\ Meryllia Luavasa
}

Follow this and additional works at: http://repository.usfca.edu/soe_fac

Part of the Education Commons

\section{Recommended Citation}

Borrero, Noah E.; Yeh, Christine J.; Tito, Patsy; and Luavasa, Meryllia, "Alone and In Between Cultural and Academic Worlds: Voices of Samoan Students" (2010). School of Education Faculty Research. Paper 2.

http://repository.usfca.edu/soe_fac/2

This Article is brought to you for free and open access by the School of Education at USF Scholarship: a digital repository @ Gleeson Library | Geschke Center. It has been accepted for inclusion in School of Education Faculty Research by an authorized administrator of USF Scholarship: a digital repository@Gleeson Library| Geschke Center. For more information, please contact repository@usfca.edu. 


\title{
Alone and In Between Cultural and Academic Worlds: Voices of Samoan Students
}

\author{
NOAH E. BORRERO AND CHRISTINE J. YEH, UNIVERSITY OF SAN FRANCISCO, PATSY TITO, SAMOAN COMMUNITY \\ DEVELOPMENT CENTER, AND MERYLLIA LUAVASA, UNDERGRADUATE STUDENT, UNIVERSITY OF CALIFORNIA, \\ RIVERSIDE
}

\section{ABSTRACT}

In a collaborative research study with a Samoan community leader and a high school student, the authors explored the academic and cultural identities of 10 Samoan high school students. In-depth qualitative interviews revealed the students' struggles with negotiating cultural and academic identities in the ecological contexts of home, peer, teacher, school, and community. Using grounded theory, the authors described the reciprocal, contradicting, and alienating nature of Samoan and academic identities in the face of negative stereotypes, competing relational obligations, and low expectations. Findings and implications also focused on cultural strengths and values such as unity, giving back to the community, and respect.

\section{INTRODUCTION}

While the population of Samoan Americans grows in poor urban settings (Stewart, 2005), there are few studies of their academic and psychological development (Liu, Murakami, Eap, \& Hall, 2008), and the data that do exist paint a troubling picture. In particular, the college graduation rate for Asian Pacific Islanders (API, including Samoans) is well below the national average (U.S. Census Bureau, 2000), and Samoan high school students have the lowest graduation rate in the San Francisco Bay Area (Samoan Community Development Center, 2008). Samoans and Tongans have the lowest per capita income across all major ethnic groups in the state of California (Stewart, 2005), and Samoan youth are overrepresented in the juvenile court system (Stewart, 2005). These negative data underscore Samoan youths' marginal societal position and suggest the ways that ethnic minority students may be culturally alienated and silenced in urban schools (Borrero, Yeh, Cruz, \& Suda, 2010).

Research evidence shows that many urban schools are victim to dominant paradigms about academic achievement that contrast sharply with ethnic minority youths' cultural values (Borrrero et al., 2010; Fine \& Weis, 2003; Kumashiro, 2000). These school-home contradictions have been discussed in terms of cultural discontinuity (Tyler et al., 2008), the tensions between ethnic and academic identities (Nasir \& Saxe, 2003), critical race achievement ideology (Carter, 2008), and experiences of the "other" (Kumashiro, 2000). These theories contend that many ethnic minority youth feel that in order to succeed in schools, they must "act White" (Fordham \& Ogbu, 1986), become "raceless" (Fordham, 1988), and choose between their academic and ethnic identities (Nasir \& Saxe, 2003). Because this research has focused primarily on African American, Latino/a, and Middle Eastern youth, it is unclear how cultural groups who may have similar experiences as the "other" are a part of this picture.

The experiences of the growing number of Samoan youth in United States (U.S.) public schools represent an untold story, yet this group embodies the experience of the "other." The "other" is defined as groups "that have been traditionally marginalized in society . . o other than the norm, such as students of color, students from under- or unemployed families, students who are female or male but not stereotypically 'masculine,' and students who are, or are perceived to be, queer. (Kumashiro, 2000, p. 26)

We expand this definition and describe "othering" as a personal, social, cultural, and historical experience involving a) cultural and racial ambiguity, b) categorization and labeling, c) hierarchical power dynamics, and d) limited access to resources (Borrero et al., 2010).

Samoan Americans are unique because they represent a number of cultural groups that have historically been included in larger racial categories (in this case Asian Americans) for practicality, rather than sociocultural meaningfulness. In fact, Samoans were included in the category of "other" Asian American until the 2000 U.S. Census. This historical act of "othering" specifically limited how Samoans were counted and the resources they received and serves as an example of how a governmental act exacerbated their perceived racial ambiguity, stigmatized their label as the other, and exemplified their low status in larger social and political power structures.

It is also possible that groups such as Samoans have been excluded from the research literature due to a lack of trust in researchers, who in their eyes may symbolize dominant and oppressive power structures. In a purposeful attempt to confront these challenges, we collaborated with Samoan community members to frame our work through a lens of relationship building and advocacy (McIntyre, 2000). Our specific interest in exploring the educational experiences of Samoan students emerges from their unique and marginal position in the United States. We investigated the cultural and educational experiences of Samoan high school students in order to give voice to a group who are subject to the cultural incongruities that research shows ethnic minority youth encounter in urban schools (Fine \& Weis, 2003; Tyler et al., 2008). We present their words in an attempt to show their emotional and 
personal experience of navigating complex, and often competing, cultural worlds. We use ecological and sociocultural perspectives to examine how different social contexts influenced the group's cultural negotiations and identity making. Using this ecological framework, our case study of Samoan American youth underscores ethnic minority students' experiences with marginalization at school. Our rationale for the study emerges from the limited research on Samoan youth despite pessimistic socioeconomic and educational data that warrant examination (Stewart, 2005).

\section{Sociocultural and Ecological Perspectives}

In using a sociocultural and ecological approach, we acknowledge that youth learn through their social interactions (Nieto, 2002). For Samoan youth, experiences with school disengagement, socioeconomic hardship, exposure to violence, and limited college access (Stewart, 2005) offer justification for exploring the multiple contexts they navigate daily. Hence, we sought to understand Samoan youths' cultural negotiations across school and home ecologies, the convergence and divergence of these contexts, and their impact on youths' perceptions about school.

Our ecological perspective (Bronfenbrenner, 1979) emphasizes youths' reciprocal exchanges across different cultural, interpersonal, and institutional settings. This approach assumes that behaviors, beliefs, and identities are inextricably bound to the spaces in which young people interact and develop. Previous ecologically based studies in urban contexts have highlighted contradicting obligations confronting ethnic minority youth as they negotiate different role expectations across important relationships and settings (Borrero \& Ych, 2010; Trickett \& Formosa, 2008; Yeh, Kim, Pituc, \& Atkins, 2008). Specifically, research on acculturation and assimilation suggests that schools are acculturative and ecological contexts that influence students' identities, relationships, family dynamics, and academic achievement (Trickett \& Formosa, 2008). Many immigrants and their children may feel pressure to assimilate, particularly in school, due to their lower social status (Berry, 2003). When youth try to adapt to school norms and develop a sense of academic identity (Nasir \& Saxe, 2003), they may experience psychological stress and alienation (Yeh et al., 2008).

\section{Cultural Identity-Making}

Research evidence shows that the making of cultural identities is an ongoing process of negotiation and integration (Nasir, 2004), as they are created, sustained, and evolving according to relevant social and interpersonal systems (Nasir \& Saxe, 2003; Samuels, 2009). Sociocultural patterns of participation (Markus, Mullally, \& Kitayama, 1997) influence identities that shift in order to meet cultural role expectations as a mandate of interdependent cultural values (Yeh \& Hwang, 2000; Yeh et al., 2005). Samoan ethnic and academic identities, when linked to cultural obligations, must also be considered in terms of possible and alternative selves (Nasir \& Saxe, 2003). Nasir and Saxe (2003) assert that conceptualizing identities as embedded in cultural activities necessitates an analysis of the development of identities within cultural settings, as well as institutional norms and beliefs (Nasir, 2004, p. 155). Ethnic minority youth must deal with the tensions between academic and cultural identities (Nasir \& Saxe, 2003) especially in schools that prioritize assimilation over maintaining cultural identity (Nieto, 2002; Suárez-Orozco \& Suárez-Orozco, 2001).

\section{Negotiating Cultural Contexts}

To combat these tensions, an important goal of ethnic identity development is bicultural competence or the ability to navigate home and mainstream American cultures (LaFromboise, Coleman, \& Gerton, 1993) to achieve a positive ethnic identity while adapting to the school community. To date, studies of racial and ethnic identity in the classroom have focused primarily on the experiences of African American students (i.e., Carter, 2008; Fordham \& Ogbu, 1986) with few exceptions (e.g., Nasir \& Saxe, 2003). The potential incongruity between Samoan cultural and academic identities has not yet been explored and must be considered in terms of ecological interactions.

Previous research with Latino/a, Black, and Asian American and Asian immigrant youth found that various familial, cultural, educational, and interpersonal settings often force these youth to negotiate multiple identities to accommodate different environmental cues (Suárez-Orozco \& Suárez-Orozco, 2001; Yeh et al., 2003; Yeh et al., 2005). We relied on this research and theory on how ethnic minority youth balance multiple ecological messages (Borrero \& Yeh, 2010; Markus et al., 1997) to provide a framework for conceptualizing how Samoan high school students negotiate divergent role expectations.

\section{METHOD}

\section{Participants}

Ten Samoan-American students from three public high schools in San Francisco participated in the study. All the students self-identified as Samoan American, members of working class families, and residents of one of the local urban neighborhoods. Six of the students were male and four were female with a mean age of 17 years (range: 16-19 years). Our selection criteria did not focus specifically on high or low achieving students or attempt to portray their differing experiences with being a Samoan student in an urban public school.

\section{Procedures}

Students were recruited via word of mouth, as well as announcements and flyers distributed to academic classes, organizations, and the Samoan community center. Interviewees were given information about the project, and each student received $\$ 20$ compensation for participation. Consent was obtained prior to participation. The audiotaped interviews lasted approximately 40 minutes, were conducted in English, and took place at a conveniently located community agency that served Samoan youth and families. The center was located near the public schools with the largest Samoan populations in the district. The interviews were 
conducted by two members of the research team (first and fourth authors of the study) who met on several occasions prior to the interviews to discuss the interview protocol, procedures, and format and to practice asking general and deeper questions.

\section{Partnership with Samoan Collaborators}

Selection of research group members. The research group included two university professors and two Samoan community members: an 18-year-old female Samoan high school senior and a 38-year-old longstanding Samoan community leader and activist. The latter two members served as collaborators in all stages of the research; both were born in the United States and attended public schools in the community. The 38-year-old community member was selected because she was the Executive Director of a community center serving Pacific Islanders in the San Francisco Bay Area. In a previous meeting with the first and second authors, she had expressed strong concern about the lack of research on Samoan youth and described many of the educational challenges they faced. The group discussed possible ways that a collaborative research project could help give voice to the Samoan community and agreed to create a research partnership. The Samoan high school student, now an undergraduate University student, was selected because she could provide insight into the lives of Samoan high school students in urban public schools. This student was also interested in gaining experience in educational research.

Research meetings. The research group met bi-weekly during one academic year to discuss all aspects of the study including: research design, time frame, recruitment, procedures, interview questions, methodology, data analysis, and plans for dissemination. These meetings also included discussions of the Samoan collaborators' own, as well as youths', educational experiences and the incongruities between school and home cultures encountered by Samoan youth.

\section{Interview Protocol}

The semi-structured interview protocol was developed with collaborators and focused on five main areas related to being Samoan: 1) identity; 2) stereotypes; 3) educational experiences; 4) community and home experiences; and 5) future goals. These topics emerged from discussions with Samoan community members, a review of relevant literature, and research interest and expertise. Questions were discussed, reworded, and then piloted with a student from a San Francisco public school to ensure cultural relevance for Samoan high school students. The interview protocol was also discussed with a Samoan community member who was part of the research team to ensure 1) clarity, 2) cultural meaningfulness and relevance, and 3) comprehensibility. The young collaborator provided insight into the experiences of Samoan students and the complexities of negotiating cultural and academic identities. She suggested ways to ask our questions and ensured that they would be relevant for Samoan high school students. The questions are presented in Table 1 .

\section{Data Analysis}

To analyze the data derived from this initial investigation of Samoan youths' educational experiences, we used grounded theory (Glaser \& Strauss, 1967) as we sought to identify emergent themes from our data without testing pre-determined hypotheses (Peterson, 2000). Interviews were transcribed, and every researcher read each of the transcripts before working independently to identify and code units (phrases or sentences) (Lincoln \& Guba, 1985) that shed light on participants' feelings about being Samoan as well as their experiences in their homes, communities, and schools. This "open coding" was used to generate as many codes as possible.

More selective coding followed, as each rater independently reread the transcripts and listed core themes with representative units. The researchers then met and discussed each theme in depth

Table 1. Interview Protocol Questions

\begin{tabular}{|c|l|}
\hline 1 & When you are asked to fill in your ethnicity on a survey, what do you choose? Why? \\
\hline 2 & What does being Samoan mean to you? \\
\hline 3 & How do you think non-Samoans view you? What are some of the stereotypes that exist about Samoans? Why do you think these stereotypes exist? \\
\hline 4 & Are there things that you do with your family that you consider "Samoan?" Any examples? \\
\hline 5 & How do your parents view Samoan culture? Do you agree? \\
\hline 6 & Who do you a hang out with? Are your friends Samoan? If not, how is it being the only Samoan? If so, do you and your friends talk about being Samoan? \\
\hline 7 & How do you feel about school? Are there a lot of Samoan students at your school? \\
\hline 8 & How do you think Samoans are viewed at your school? Why? Do you have specific examples that show these views? \\
\hline 9 & What do you think your teachers think about Samoan students? Why? Are these views correct? \\
\hline 10 & What types of things are important to make up a community? What communities are you connected to? Is there a Samoan community in San Francisco? \\
\hline 11 & Tell me about how your church community is related to the Samoan community. \\
\hline 12 & $\begin{array}{l}\text { What are some of your future goals? What are your goals as a student? What are your goals as a member of the Samoan community? Are your family } \\
\text { and friends supportive of your goals? }\end{array}$ \\
\hline
\end{tabular}


(Strauss \& Corbin, 1998) to identify possible sub-categories. The discussion continued until consensus was reached, and each researcher read a final time to identify representative quotes for each theme. These quotes were among those selected for inclusion in the results section and were checked for significance and accuracy by our collaborators.

\section{FINDINGS: BEING SAMOAN AND TRYING TO SUCCEED ACADEMICALLY}

The emergent themes and selected quotes that are representative of the experiences of the participants are presented with the understanding that while the descriptions are not indicative of the experiences of all Samoan youth, they introduce and highlight the voices, challenges, and strengths of a historically silenced group. The themes represent narratives about being Samoan (unity, respect, church as a foundation of Samoan culture, giving back to the community), trying to be academic (negotiating stereotypes; messages from parents, teachers, and peers; living in poverty), and being alone.

\section{Being Samoan}

We explored the students' narratives about their Samoan cultural identities and found that they perceived identity making in Samoan culture to be clearly defined by a set of preconceived notions about what it means to be part of a Samoan family and community.

Unity in Samoan culture. Student narratives revealed Samoan identities to be immersed in descriptions of the importance of interconnectedness between families in the Samoan community:

When I think of Samoan people, I think of unity. We are a small community so I mean, like everybody says, every Samoan knows each other, and I mean, to some extent that is kind of true. (Dina, 18)

Our participants related that, for the most part, Samoans assume that with unity come a shared life space, mutual understanding, a common set of values, and committed friends and family. For our sample of students, being Samoan may also represent a constant negotiation of dualities, for example, choosing between going to school or helping at home, with each decision reflecting their cultural priorities and identities.

Respect and the importance of extended family and elders in Samoan culture. All students told stories about the cultural expectation to respect their elders and prioritize family relationships above all else. Lima (19) spoke of respect as a foundation of being Samoan that was passed on to her through her family:

You know, when I think [about being] Samoan, I think on a personal level I will always think of my grandparents first and foremost. And one thing that I definitely learned from them and carry with me until this day is having the ultimate respect for people.
Failalo (18) spoke more specifically about the role of respect and the fact that this cultural expectation does not simply stop when you become 18 years old. He said,

You can be twenty-something, and if you are living at home with your parents, you're still a kid. Respect is big. I mean, it should be big all the time, but like they really, really, really push respect.

For these youth, being Samoan means demonstrating specific culturally dictated behaviors such as never initiating eye-contact with an elder and never talking back to a family member or elder. Our participants reported that this cultural emphasis on respect was disrupted in the school context, where they continually watched classmates act out and verbally confront adults. They thought that being disrespectful to teachers was part of the expectation of being a student and part of the school culture. This dynamic contradicted cultural assumptions about respect and made it hard for students to negotiate how to be a Samoan and a student simultaneously.

Church as a foundation of Samoan culture. Students described church, unlike school, as a site where being Samoan is expected and reinforced. The role of church was strongly communicated by all participants as they spoke openly of their connection to church, the pressure from their elders to attend church, church as a social network for the Samoan community and a place where Samoan language and culture is fostered. Isolina (17) stated:

I know that church is very much a part of all or our lives. I think actually that that is one of the only places we still continue to practice a lot of our cultural tradition-especially in the Samoan Protestant Church ... I know that church is something that brings us all together.

Attending a Samoan church illuminated both feelings of unity and disconnect with Samoan culture. While the church was the place where Samoan values were most prominent, for many youth being in church was a harsh reminder of the cultural losses that occurred across generations. More assimilated Samoan youth often felt disconnected when services were conducted in Samoan, since they had limited knowledge of the language: "[Church] is not that interesting only because it is in Samoan, and I don't know that much Samoan" (Vai, 17).

In this sense church is a space where being and becoming Samoan is highly valued but not always attainable, and the spaces of church and school do not necessarily support one another. For example, the young people are expected to spend their entire Sunday at church, limiting the time they have to spend on schoolwork. These competing obligations were left for students to negotiateoften with tensions and contradictory feelings of guilt about their cultural identity.

Giving Back. Perhaps one of the strongest obligations associated with unity is the desire to give back to the Samoan community. For 
most participants, this entailed taking an active role in the local Samoan community and helping younger Samoans. Dom, 19, personalized his desire to give back to the community through sharing his own challenges growing up:

Hanging around on the corners selling drugs, this and that, and "there's no point of you going to school." And now that I'm a senior, you know I want to do better. I want to put myself out there and be a role model for the younger Samoans, especially my little nephews to look up to me and say, "if uncle Dom can, why can't I?" I don't want them to fall into the other one's footsteps; you know be a low life.

Students expressed their gratitude to other Samoans in the community who were giving back and expressed a desire to join the cause. One student talked about a speaker who came to his school and reached out specifically to the Samoan students. He recalled the speaker saying that Samoans were significantly over represented in the prison system, a reality that affected him and drove him to become involved in his community:

The fact that I want to be involved in prisons and I'm Samoan should say a lot. I'd like to work primarily with Samoan people. (Solo, 18)

\section{Trying To Be Academic}

Students expressed the idea that life at school was distinct from life at home and spoke of the academic and social expectations held by school personnel as creating barriers they needed to overcome in order to feel successful academically. Beyond going to class, or even graduating, however, students described feeling strong forces working against them if they tried to develop a sense of themselves as "Samoan" and as "student."

Stereotypes of Samoans. All ten interviewees noted prominent Samoan stereotypes, the most common that Samoans are physically large, athletic, strong, lazy, proud, and dangerous. Students spoke of the effect of these stereotypes on their social interactions at school and on the streets:

Sometimes when I'm with certain of my friends, people look at us like, you know - "they're just up to no good; they gonna do something."That's how people look at us when we are together. (Julia, 17)

This stereotype of Samoans as big and dangerous overlapped with the themes of respect and unity:

[People] leave you alone because "your family's gonna come after me."You know, we roll in packs and we're dangerous. And if you do something to one, you do something to everybody. They're all gonna come after you. You know, like we are some type of Mafia people. (Sepe, 19)

These stereotypes were internalized by some students and had an effect on how they perceived others' expectations of them. Not only did they feel that others saw them as potentially dangerous on the streets and good on the athletic fields, but they felt that these expectations negated others' perceptions that they could do well in school: "We're athletic and that is about it. You know, it was a surprise to see a Samoan excelling in academics over athletics" (Solo, 18).

Messages from parents, teachers, and peers. Students noted that parents held high expectations for them at home (for example, respecting elders in the community and attending church), but they had little involvement in school activities. Some students reported that parents could not help them with schoolwork because of their language differences and low academic backgrounds. Not only did this create a divide between students' lives at school and their lives at home, but in some cases it served to distance them from their parents and their Samoan cultural traditions:

My dad, he doesn't speak English very well, and I think that kind of - it kind of - limited our relationship with our father growing up ... He knew we were excelling in English, but my dad-you know - there came a point where there wasn't much he could do ... because there wasn't anything he could help us with; communication was limited. (Sepe, 19)

Beyond language, students reported that their parents did not really understand what school was like. Several students referred to their parents' lives growing up "back in the Islands," and reported that they thought of life in America today as "way more complicated." They noted that parents wanted them to stay out of trouble at school but did not necessarily become involved with their homework or grades.

Students reported that the messages they received from teachers and other school personnel reflected low academic expectations, evident in many different ways, especially the reinforcement of the idea that Samoans are troublemakers:

My first experience was going to school and the principal thinking I was cutting my own class. [She was] thinking that I was in the wrong class and that I was supposed to be somewhere else - simply because I looked Samoan. And I didn't get it the whole time. I did not realize that their idea of Samoan kids was that they were bad, they're liars, they don't do good, they're cutting class, you know, they misbehave. And I didn't realize that she just slapped a label on me the first day cuz I was wondering why she was accusing me of cutting my own class. (Lima, 19)

Other students spoke more specifically about the comparisons teachers made between them and students from other cultural groups and immediately labeled them:

It was freshmen year and my first period class and then she [my teacher] said my name and I was like "yeah" and she was like "Are you Samoan?" And I was like "yeah." She told me to go sit in the back and she said "don't play this whole 
semester" and that I should take school serious. Just cuz I was Samoan. (Pika, 16)

The participants discussed the fact that the majority of their peers did not share their goals to succeed in school and graduate. Most students talked about their friends (usually other Samoans) urging them to cut classes with them and keep school a low priority: "my friends . . . always try to pull me down. But I always tell them ... . don't put me in the same track you in. Don't pull me down" (Vai, 17).

Other students spoke more specifically about having to distance themselves from the behaviors of their Samoan friends. One student said:

Hopefully other Samoan kids will realize they don't have to be like that. They don't have to be smokers who enjoy stealing cars and riding them back up to school, and, you know, kids getting high, getting pregnant. Why is it that some people feel the need to believe that they can excel, but other people feel they already accepted the fate somebody else gave them? (Sepe, 19)

Without academic support at home and bearing the brunt of low expectations by teachers and administrators at school, students reported that they had few places to turn for support at school. Additionally these students found little support from their Samoan peers and thus, were forced to look elsewhere for meaningful relationships. Like students' discussions about stereotypes, this theme portrays the barriers and mixed messages that students face.

Poverty. Interviewees discussed poverty as a daily reality; they live in gang-infested neighborhoods where they have to "watch their back" when they leave the house. They spoke about drug deals, not feeling safe, and needing to stay close to one another on the streets. They talked about life in the "projects" and the difficulty of escaping the ways of their surroundings. Additionally, students reported that life on the streets often carried over to life in the hallways at school. Fights and drug deals were a part of their school experience, and interviewees reflected on the tension between looking out for their fellow Samoans and trying to stay out of trouble.

For these youth, poverty was a barrier to academic achievement. As Samoans, they were expected to give of what they had to others in need. This could mean taking care of younger family members, dedicating multiple days of a week to a religious ceremony, or giving money to a family in need. As a priority above all else, this cultural expectation, when combined with life in poverty, made school success a challenge.

\section{Being Alone: The Space between Being Samoan and Being a Student}

Students reported that they felt alone as they faced the challenges confronting them as Samoans in a U.S. city, in U.S. schools, with ambitions to graduate from high school. This aloneness came from the fact that they were negotiating very different cultural realities at home and at school, but it also came from having ambitions that their peers did not share:

I wanted to identify with other Samoan kids, but none of them was excelling like I was, and none of them had any plans for college. And I felt like I wanted so badly to have them be a part of what I was going through . . . [But] They had different stress coming from something else-_okay how am I gonna make it past junior year? How am I gonna stop cutting? I need to quit smoking, it's doing bad for me." It was like our struggles were so different, and it was sad because I felt alone, and I wanted so much to share it with other Samoan kids. (Lima, 19)

The impact of this aloneness was internalized by some students and resulted in their thinking that their desires to succeed academically had distanced them from their Samoan friends, and this was difficult. One student stated:

I feel like I'm the only one. Yeah, it's really weird. I mean it feels, yeah, it does feel weird. I mean I've learned to come accustomed to it but I don't know . . you long for like somebody to have that connection, but you don't really have anybody there. (Dina, 18)

This aloneness resonated throughout the interviewees' descriptions of life as a Samoan trying to succeed in school. They reported that not only is life at home different from life at school, but the two realities offered no support for each other. Being Samoan meant respecting their elders, yet there were times at school when their elders did not respect them. They said that being Samoan also means being unified, yet, to succeed in school, they must break away from their Samoan peer group, leaving them somewhere in between - trying to retain their Samoan identity and building an academic identity.

The students know that what is lacking in their experience at school is the presence of meaningful relationships (Trickett \& Formosa, 2008; Yeh et al., 2008). Without the comfort of peer support and motivation from caring teachers, students feel alone as they try to make sense of the cultural expectations (Nasir, 2004) at school. It is the space in between being Samoan and being a student-the "other"- that makes these youth feel alone.

\section{DISCUSSION: ALONE AND IN BETWEEN}

The themes of the interviews illuminate the difficult position in which these Samoan youth find themselves, living in an urban environment, living up to family expectations, and attending urban public schools. The negotiation of these contexts proved challenging, as they reported feeling caught in between the cultural expectations of being Samoan and being academic. This discussion of the findings will show how these students' voices represent their unique experiences as Samoans and also the "othering" of some students of color across cultural contexts (Borrero et al., 2010). While previous research has documented cultural incongruities between students' home and school contexts, we 
focus on the personal and emotional experiences of being alone and in between cultural worlds. Our interviews and the quotation that were taken from them attempt to give voice to this experience of being alone, an issue that is further informed by the geographic and cultural isolation of the Samoan cultural group. Hence, in our discussion of the findings we clearly articulate how "being Samoan" and "being academic" pose cultural and educational barriers and dilemmas that embody the experience of Samoan youth in schools. We frame this discussion within the literature that highlights the cultural incongruities that face urban youth of color at school (e.g., Fordham \& Ogbu, 1986; Nasir \& Saxe, 2003; Tyler et al., 2008) while also attending to aspects of these Samoan students' experiences that speak to their position as the "other" (Borrero et al., 2010; Fine \& Weis, 2003; Kumashiro, 2000).

\section{Multiple Contexts, Multiple Expectations}

The prevalence of respect and the solidarity of the Samoan family structure were communicated clearly and continually. Participants reported that they were to respect and obey their elders, place family above all else, and participate in Samoan cultural and religious traditions. These expectations - unity and respect - were discussed as daily cultural realities. For these youth, being Samoan was unspoken, unconditional, and reinforced through planned behaviors, expected conversations, and feelings of insecurity. It was an understanding that other Samoans provided care and "protection in times of need."

When it came to schoolwork or other aspects of students' lives outside of the family network, they felt little support, communicated through students' discussions about the lack of parental support in school activities and academic expectations. So, at home, students' school lives were distant and even conflicting. Some of these complex family dynamics may be explained in terms of generational change and intergenerational family conflict. As children grow up, cultural gaps between parents and children become more pronounced (Huang, Ying, \& Arganza, 2003; Yeh et al., 2008). In addition, as seen in our data, many ethnic minority youth have numerous familial obligations they must learn to balance and maintain.

The students discussed their lives with their friends in two contexts-on the streets and at school. They again discussed the role of Samoan unity on the streets. This was where they felt the support of their Samoan friends and appreciated a sense of shared protection and solidarity from their community (Markus \& Kitayama, 1991; Nasir \& Saxe, 2003; Yeh \& Hwang, 2000; Yeh et al., 2005). In contrast, students talked about their Samoan peers "bringing them down" at school or encouraging them to behave in ways that interfered with school success. Interviewees did not feel that their Samoan friends were supportive of their academic goals, and this created a divide between their connections with their peers and their desires to do well in school. Teachers held low expectations for them, so, in the school context, Samoan unity was incongruous with the academic identity fostered by teachers, administrators, and a school system with strict expectations for student behavior (Fine \& Weis, 2003; Nasir \& Saxe, 2003).

Balancing these multiple cultural realities and expectations often left students feeling alienated and alone (Kumashiro, 2000). Reflecting back to participants' comments about the contradictions between church and school expectations we noted that one student described how Samoan youth are obligated to attend Samoan funerals that last several days, causing students to miss multiple days of school. Their teachers did not let them make up the work, and in fact, used their absences as further evidence of their lack of academic motivation. Because of the relative isolation of the Samoan cultural group and the lack of awareness of their traditions, it is this type of cultural divide that defines their experience as the "other" (Borrero et al., 2010) and leaves them alone to fend for themselves if they are to retain their Samoan cultural identity and pursue an academic identity (Nasir \& Saxe, 2003).

In the process of negotiating different social worlds, the participants described their shifting identities as Samoans and students (Nasir, 2004), and clear assets that the Samoan community fosters in their young people. From their perspective, Samoan youth grow up with respect, a sense of unity with fellow Samoans, and a strong church connection, and these assets contribute to a strong desire to give back to the Samoan community. Students reported that they also face tremendous challenges that impede their abilities to feel successful or welcome as members of the Samoan community and as students in school (Nieto, 2002). These blockades came in the form of poverty, negative stereotypes, low expectations by school personnel, and peers who do not understand academic ambition.

A false assumption in traditional paradigms for academic ambition and achievement is that students have the power and choice to create academic identities. However, choosing school success often means rejecting cultural obligations and confronting the stereotypes that dictate their place in schools (Fine \& Weis, 2003). Low expectations add a dangerous undercurrent to the already strong forces working against students' academic motivation and create a racially hostile environment for student identities (Carter, 2008). Similar to the findings of research with other ethnic minority youth (e.g., Fordham \& Ogbu, 1986; Nasir \& Saxe, 2003), in our study, Samoan youth did not see themselves as being empowered to pursue the expected academic trajectory set by the teachers and administrators who appear to "enforce" the rules. Further, as the "others," they learned that their lives at home could not be integrated into their lives at school (Borrero et al., 2010).

As a result, being Samoan American entails incorporating competing and mixed messages about school success. Because of the relatively small population and the cultural and geographic isolation of Samoan youth, the social interactions and relationships that are needed to help students develop a sense of identity (Trickett \& Formosa, 2008; Yeh et al., 2008) at school are missing. Hence, these youth are left to fend for themselves if they want to succeed academically. 
The aloneness expressed by these Samoan youth illuminates larger issues at stake for students of color in schools (Tyler et al., 2008). School is not a place where students should feel alone, yet many students share the sentiment expressed by these students about being the "other" at school (Fine \& Weis, 2003; Kumashiro, 2000). The "othering" of Samoan students reveals the alienating experience of youth as marginalized and in the margins. "Othering" is reinforced by the pathologizing of diversity in schools (Kumashiro, 2000), the juxtaposition of academic and cultural worlds, and the delineation of insiders and outsiders by those in power (Borrero et al., 2010; Fine \& Weis, 2003).

Taken together, our findings support existing literature on the cultural incongruities facing urban youth of color (e.g., Tyler et al., 2008) and offer insight into the experiences and voices of Samoan students whose identities are mutually co-constructed in multiple spaces, with multiple roles and expectations. For example, Samoan youths' cultural identities at home influence their perceptions of and interactions in the classroom. Assumptions about identity-making suggest individual choices between dichotomous, opposing cultural worlds with assimilationist agendas. However, as expressed by our interviewees, many Samoan youth hold simultaneous cultural obligations and tensions that prompt ambiguous and silenced identities, mixed messages, and unspoken feelings.

\section{LIMITATIONS}

The findings of this research cannot be generalized across Samoan or API populations in urban schools. Our study focuses specifically on the experiences of 10 low-income Samoan high school students in a specific community in California. We also cannot generalize the low expectations from teachers and limited involvement from family members in this study as indicative of the Samoan experience. However, our in-depth interviews and analysis begin to tell the unique story of how Samoan youth, as the "other," negotiate academic and cultural worlds often feel alone during this process.

\section{RECOMMENDATIONS FOR FUTURE RESEARCH}

Future research with larger samples of Samoan and API students would help to determine whether our findings represent the unique experiences of Samoan youth or more generalized experiences of urban youth of color. Specifically, additional studies could investigate how high versus low achieving Samoan youth negotiate academic and cultural worlds across family, peer, and school relationships and expectations. Further research may incorporate mixed-method approaches that include more deliberate quantitative as well as in-depth qualitative explorations that allow a more informed understanding of the unique challenges and assets of this group.

Our findings help shape our growing theoretical understanding of how Samoan high school students' academic and ethnic identities reflect the cultural incongruities found with other youth of color (Tyler et al., 2008) and how these identities cannot be separated from the social, educational, and cultural systems in which youth interact. Our research begins to highlight how schools and teachers may contribute to racially unwelcoming environments that leave "othered" youth feeling that they cannot simultaneously embrace their cultural and academic identities (Kumashiro, 2000).

\section{IMPLICATIONS FOR SCHOOLS AND COMMUNITIES}

Our findings have the potential to inform teaching practices as well as school interactions with families and communities. Our Samoan participants did not feel supported by their peers, families, and teachers in their academic aspirations; hence, schools must consider opportunities to eliminate negative stereotypes, encourage positive ethnic identities, and create curriculum that is culturally inclusive. Cultural assets, such as the Samoan values of unity and giving back, should be recognized and used to help eradicate barriers to academic achievement and feelings of belonging.

Our partnership with community members was purposeful in terms of our research methodology and our desire to provide service to the community. Specifically, our collaboration extends beyond traditional models of qualitative research by incorporating cultural validity, trustworthiness of the data, and meaningfulness of research questions (Yeh \& Inman, 2007). Our work with Samoan youth and community members provided a culturally relevant model for future school, university, and community partnerships with marginalized groups. This relationship also sought to empower our Samoan collaborators to be social justice advocates, researchers, and role models for the next generation of Samoan youth (Israel et al., 2003).

\section{References}

Berry, J. W. (2003). Conceptual approaches to acculturation. In K. M. Chun \& P. Organista (Eds.), Accuturaltion: Advances in theory, measurement and applied research (pp. 17-37). Washington, DC: American Psychological Association.

Borrero, N. E., \& Yeh, C. J. (2010). Ecological language learning among ethnic minority youth. Educational Researcher. 39(8), 571-581.

Borrero, N. E., Yeh, C. J., Cruz, I., \& Suda, J. (2010). School as a context for "othering" youth and promoting cultural assets. Teachers College Record. Retrieved from http://www.tcrecord.org/Content.asp?ContentId $=16246$.

Bronfenbrenner, U. (1979). The ecology of human development. Cambridge, MA: Harvard University Press.

Carter, D. J. (2008). Achievement as resistance: The development of a critical race achievement ideology among Black achievers. Harvard Educational Review, 78(3), 466-497.

Fine, M., \& Weis, L. (2003). Silenced voices and extraordinary conversations: Re-imagining schools. New York, NY: Teachers College Press.

Fordham, S. (1988). Racelessness as a factor in Black students' success: Pragmatic strategy or pyrrhic victory? Harvard Educational Review, $58(1), 54-84$.

Fordham, S., \& Ogbu, J. U. (1986). Black students' success: Coping with the burden of "acting White." Urban Review, 18(3), 176-206.

Glaser, B. G., \& Strauss, A. L. (1967). The discovery of grounded theory. Chicago, IL: Aldine. 
Huang, L.,Ying,Y., \& Arganza, G. (2003). Chinese American children and adolescents. In Gibbs \& L. N. Huang (Eds.), Children of color: Psychological interventions with minority children (2nd ed., pp. 187-228). San Francisco, CA: Jossey-Bass/Wiley.

Israel, B., Schulz, A., Parker, E., Becker, A., Allen, A., \& Guzman, J. R. (2003). Critical issues in developing and following community based participatory principles. In M. Minkler \& N. Wallerstein (Eds.), Community-based participatory research for health (pp. 53-76). San Francisco, CA: Jossey-Bass/Wiley.

Kumashiro, K. K. (2000). Toward a theory of anti-oppressive education. Review of Educational Research, 70(1), 25-53.

LaFromboise, T., Coleman, H. L. K., \& Gerton, J. (1993). Psychological impact of biculturalism: Evidence and theory. Psychological Bulletin, II4, 395-412.

Lincoln, Y. S., \& Guba, E. G. (1985). Naturalistic inquiry. Newbury Park, CA: Sage.

Liu, C., Murakami, J., Eap, S., \& Hall, G. (2008). In N. Tewari \& A. Alvarez (Eds.), Asian American psychology: Current perspectives. Who are Asian Americans? An overview of history, immigration, and communities (pp. 1-29). New York, NY: Taylor \& Francis Group.

Markus, H. R., \& Kitayama, S. (1991). Culture and the self: Implications for cognition, emotion, and motivation. Psychological Review, 98, 224-253.

Markus, H., Mullally, P., \& Kitayama, S. (1997). Selfways: Diversity in modes of cultural participation. In U. Neisser \& D. Jopling (Eds.), The conceptual self in context: Culture, experience, and self-understanding (pp. 13-61). Cambridge, UK: Cambridge University Press.

McIntyre, A. (2000). Constructing meaning about violence, school, and community: Participatory action research with urban youth. The Urban Review, 32, 123-154.

Nasir, N. S. (2004). "Halal-ing" the child: Reframing identities of resistance in an urban Muslim school. Harvard Educational Review, 74(2), 153-174.

Nasir, N. S., \& Saxe, G. B. (2003). Emerging tensions and their management in the lives of minority students. Educational Researcher, 32(5), 14-18.

Nieto, S. (2002). Language, culture, and teaching: Critical perspectives for a new century. Mahwah, NJ: Lawrence Erlbaum Associates, Inc.

Peterson, S. (2000). Multicultural perspective on middle-class women's identity development. Journal of Counseling \& Development, 78, 63-71.

Samoan Community Development Center. (2008). Summary: Samoans in public schools. San Francisco, CA: Samoan Community Development Center.

Samuels, G. M. (2009). Using the extended case method to explore identity in a multiracial context. Ethnic and Racial Studies, 32(9), 1599-1618.

Stewart, J. Y. (2005). Data reveal hard truths for islanders; No longer lumped in studies with immigrants from Asia, Samoans see a portrait of a troubled community. Los Angeles Times, September 26.

Strauss, A., \& Corbin, J. M. (1998). Basics of qualitative research: Techniques and procedures for developing grounded theory. Newbury Park, CA: Sage.

Suárez-Orozco, C. \& Suárez-Orozco, M. M. (2001). Children of immigration. Cambridge, MA: Harvard University Press.

Trickett, E. J., \& Formosa, D. (2008). The acculturative environment of schools and the school counselor: Goals and roles that create a supportive context for immigrant adolescents. In H. L. K. Coleman \& C. J. Yeh (Eds.), Handbook of school counseling (pp. 79-94). New York, NY: Routledge, Taylor \& Francis Group.
Tyler, K. M., Uqdah, A. L., Dillhunt, M. L., Beatty-Hazelbaker, R., Conner, T., Gadson, N., Henchy, A., Hughes, T., Mulder, S., Owens, E., Roan-Belle, C., Smith, L., \& Stevens, R. (2008). Cultural discontinuity: Toward a quantitative investigation of a major hypothesis in education. Educational Researcher, 37(5), 280-297.

U.S. Census Bureau (2000). We the people: Pacific Islanders in the United States. Census 2000 SpecialReports. Retrieved on 2008, July 14 from http://www.census.gov/population/www/cen2000/briefs /index.html.

Yeh, C. J., Arora, A. K., Inose, M., Okubo, Y., Li, R. H., \& Greene, P. (2003). The cultural adjustment and mental health of Japanese immigrant youth. Adolescence, 38(151), 481-500.

Yeh, C. J., \& Hwang, M. (2000). Interdependence in ethnic identity and self: Implications for theory and practice. Journal of Counseling and Development, 78, 420-429.

Yeh, C. J., \& Inman, A. G. (2007). Qualitative data analysis and interpretation in counseling psychology: Strategies for best practices. The Counseling Psychologist, 35, 369-403.

Yeh, C. J., Kim, A. B., Pituc, S. T., \& Atkins, M. (2008). Poverty, loss, and resilience: The story of Asian immigrant youth. Journal of Counseling Psychology, 55, 34-48.

Yeh, C. J., Ma, P-W., Madan, A., Hunter, C. D., Jung, S., Kim, A., Akitaya, K., \& Sasaki, K. (2005). The cultural negotiations of Korean immigrant youth. Journal of Counseling and Development, 83, 172-181.

Noah E. Borrero is an assistant professor in the Department of Teacher Education at the University of San Francisco. He can be reached at 2130 Fulton Street, San Francisco, CA 94117 or at neborrero@usfca.edu.

Christine J. Yeh is a professor and chair of the Department of Counseling Psychology at the University of San Francisco. She can be reached at 2130 Fulton Street, San Francisco, CA 94117 or at cjyeh@usfca.edu.

Patsy Tito is Executive Director of the Samoan Community Development Center. She can be reached at 2055 Sunnydale Avenue, San Francisco, CA 94134 or scdc_sf@pacbell.net.

Meryllia Luavasa is an undergraduate student at University of California, Riverside. She can be reached at meryllia@yahoo.com. 
Copyright (C) Trustees of Boston University. 